\title{
Getting Proactive: Cultural And Procedural Drivers Of Managerial Motivation To Act
}

Alexander Rusetski, York University, USA

\begin{abstract}
The importance of managers' proactive behaviors in the workplace is well documented. While previous studies have focused on dispositional drivers of proactive behaviors, this paper investigates situational - cultural and procedural - factors that affect managers' motivation to proactively engage in behaviors aimed at improving performance of their firms. Results of a survey of brand managers suggest that consumer orientation and adhocracy culture tend to increase proactive behaviors, while technology strategic orientation decreases managers' motivation to act. Interestingly, the cultural characteristics of a firm are significantly more effective in motivating managers than evaluation and compensation procedures.
\end{abstract}

Keywords: brand management; proactive behaviors; motivation; organizational culture; strategic orientation; compensation

\section{INTRODUCTION}

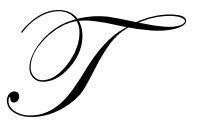

he importance of employees' proactive behaviors for a firm's success has been documented in numerous studies in marketing and management (see de Jong \& de Ruyter, 2004 and Crant, 2000 for reviews). Being proactive involves behavioral initiative aimed at changing a current situation and challenging the status quo as opposed to passively adapting to the circumstances (de Yong \& de Ruyter, 2004). In dynamic business environment, when employees are willing to take charge and work toward resolving unexpected and/or poorly defined problems, effectiveness of a firm's response to competitive threats or opportunities presented by changes in the environment increases significantly (e.g., Kirkman \& Rosen, 2009; Bateman \& Crant, 1999; Kim et al., 2009). Therefore, a lot of attention has been paid to understanding the drivers of proactive behaviors. Previous studies focused on several areas, investigating managers' proactive behaviors related to specific marketing activities (e.g., de Jong \& de Ruyter, 2004, Pitt, Ewing, \& Berthon, 2002; Spiro \&Weitz, 1990). While some situational factors were investigated, proactive behaviors were largely seen as a function of a personal disposition (e.g., Bateman \& Crant, 1993, Kim et al. 2009). At the same time, studies in psychology have shown that while some individuals may be more inclined to act than others, this inclination has both situational and dispositional roots (Higgins, 1997). This logic ties together studies that investigated organizational and workplace characteristics influencing proactive behaviors and studies that looked at managers' dispositions. Regulatory focus theory (Higgins, 1997; Crowe \& Higgins, 1997) suggests that the environment may have an effect on the overall motivation of managers to act or to remain passive above and beyond their personal dispositions. Not only the particulars of the workplace, but also the overall atmosphere of the organization, its strategic goals, and such overarching factors as organizational culture, can be expected to exert influence on managers' motivation to behave proactively (Crant, 2000).

The goal of this study is to investigate how the environment, specifically characteristics of organizational design, like the system of incentives, strategic orientation, or organizational culture, affects managers' willingness to engage in proactive behaviors. Rather than analyzing behaviors, this study investigates drivers of the motivation behind such behaviors by introducing the concept of motivation to act - the extent to which managers are willing to engage in proactive behaviors. Although behaviors are driven by motivation, other factors, like fears or the need to 
comply with external demands and pressures, can also affect them. By focusing strictly on the motivation, we aim at avoiding the compounding of factors. Additionally, we expect to clarify the role of different categories of potential drivers - procedural as opposed to cultural - in motivating managers to act.

\section{MOTIVATION TO ACT AND ITS DRIVERS}

The extent to which managers engage in proactive behaviors that change the current situation and challenge the status quo, as opposed to passively adapting to the circumstances (de Yong \& de Ruyter, 2004), has been studied extensively (e.g., Kim, Hon, \& Crant, 2009; Crant, 2000, 1995; Bateman \& Crant, 1993; Aspinwall \& Taylor, 1997). Several studies focused on personal dispositions as drivers of proactive behaviors. It has been demonstrated that personality traits, like the need for achievement or the need for dominance (Bateman \& Crant, 1993), are positively related with proactive behaviors. The notion of proactive personality has been suggested to capture the individuals' disposition toward engaging in active role orientations, such as initiating change and influencing their environment (Kim et al., 2009; p. 103). While looking at the dispositional explanations of proactive behaviors, studies in this research stream acknowledge that the situation can also affect the willingness to engage in proactive behaviors (Crant, 2000; Bateman \& Crant, 1993). This idea echoes the developments in psychology, specifically the area investigating human self-regulation.

Regulatory focus theory (Higgins, 1997) suggests that people are most inclined to act (i.e., have a promotion regulatory focus) when they see the situation as framed around possible gains, their most salient needs pertain to nurturance, and self-regulation is driven by aspirations and ideals. Conversely, people are expected to demonstrate avoidance behaviors (i.e., prevention regulatory focus) when the situation is framed around possible losses, security needs are most salient, and responsibilities and ougths are the main motivational drivers.

Willingness to act when there is a choice to remain passive can be seen as one of the main drivers of proactive behaviors (Crant, 2000, Bateman \& Crant, 1999). In order to capture the inclination to behave proactively, we introduce the concept of motivation to act - the extent to which a manager feels enthusiastic about and committed to taking an action. Based on the logic of regulatory focus theory, motivation to act should be related to a manager's promotion regulatory focus that is defined by his or her focus on pursuit of achievements, desire to demonstrate professional ability, and the perceived risk-tolerance of the organization (Brockner, Higgins, \& Low, 2004).

Several aspects of organizational design may influence managers' motivation to act (see Figure 1). First, evaluation and compensation practices can frame the situation for managers around gains vs. losses and thus impact motivation to act. Second, the goals and culture of an organization can elicit particular needs and aspirations among managers (Crant, 2000).

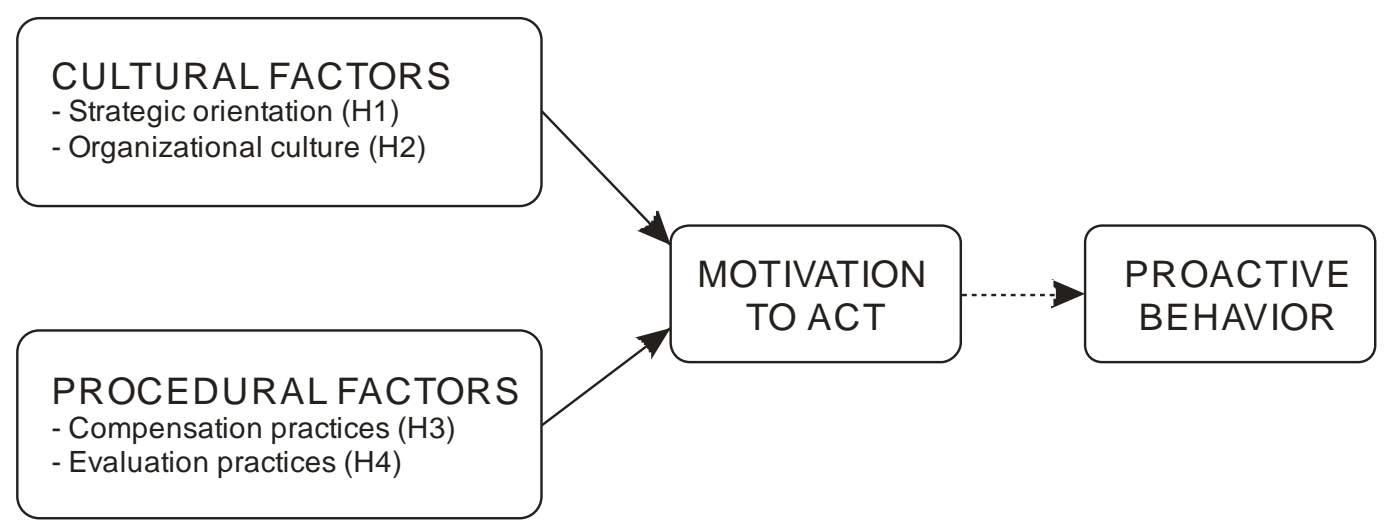

Figure 1: Motivation to Act and its Antecedents 
While manipulating the system of incentives is relatively easy, changing culture and strategic orientation is more difficult and time-consuming (e.g., Noble, Sinha, \& Kumar, 2002). The goal of this study is to investigate the relationship between these factors and managerial motivation to act, but additionally to study what kind of drivers procedural vs. cultural - have a stronger effect and therefore should be prioritized by senior managers.

\section{THEORY AND HYPOTHESES}

The strategic orientation of a firm or business unit is conceptualized as strategic directions implemented by a firm to create proper behaviors for continuous superior performance of the business (Gatignon \& Xuereb, 1997, p. 78). Three possible strategic orientations are suggested: 1) consumer (i.e., a firm with the ability and will to identify, analyze, understand, and answer user needs), 2) technological (i.e., the ability and will to acquire a substantial technological background and use it in the development of new products), and 3) competitor (i.e., a firm with the ability and will to identify, analyze, and respond to competitors' actions). Consumer and competitor orientations imply the ability and readiness to proactively seek new information and act quickly in response to changes in the environment and are expected to motivate managers (Narver \& Slater, 1990). On the other hand, technological orientation should be associated with heavy investments in R\&D and will prompt restraint from managers aimed at the avoidance of mistakes, diminishing the motivation to act immediately (Gatignon \& Xuereb, 1997). Hence,

H1: The degree of a) consumer orientation and b) competitor orientation of the business unit will be positively related to managers' motivation to act, while the degree of c) technology orientation will be negatively related to motivation to act.

Organizational culture is defined as the pattern of shared values and beliefs that helps individuals understand organizational functioning and provides norms for behavior in the organization (Deshpande \& Webster, 1989, p.4). Deshpande, Farley, and Webster (1993) discuss four types of organizational culture: 1) Adhocracy culture promotes flexibility, entrepreneurship and creativity; 2) Market culture values customer focus, goal achievement, productivity, and efficiency; 3) Hierarchy culture is characterized by order, efficiency, stability, and control; and 4) clan culture emphasizes cohesiveness, participation, and teamwork. The four cultures differ in terms of the nature of organizational processes (organic for adhocracy and clan vs. mechanistic for hierarchy and market) and the focus of activities (internal maintenance for clan and hierarchy vs. external positioning for adhocracy and market).

According to Deshpande, Farley, and Webster (1993, p. 25), clan and hierarchy cultures do not emphasize immediate performance gains; therefore, we don't expected them to have an effect on motivation to act. Conversely, adhocracy and market cultures emphasize seizing market opportunities (adhocracy) and achieving competitive advantage in the market (market culture). With its organic organizational processes and emphasis on pursuit of opportunities, adhocracy culture will prompt high motivation to act. In a market culture, although it does emphasize competitive performance, the mechanistic nature of organizational processes will not stimulate proactive opportunity-seeking behaviors, decreasing motivation to act. Therefore:

H2a: Adhocracy culture will be positively related to motivation to act.

H2b: Market organizational culture will be negatively related to the motivation to act.

It is possible to argue that higher motivation to act associated with adhocracy and market organizational cultures may be driven by dispositions of mangers selected through hiring procedures. We address this concern by using managers' dispositions toward proactive behaviors as a covariate in our analysis.

The most readily available motivational tool in a firm is the system of incentives. The goal of such systems is to align the interests of managers with those of the firm (Jensen \& Meckling, 1976; Martynov 2009) and elicit desired behaviors. Numerous studies that use rewards versus penalty-based systems of incentives to manipulate regulatory focus report that respondents are significantly more likely to behave proactively when presented with immediate rewards rather than penalties (e.g., Higgins, Shah, \& Friedman, 1997; Shah, Higgins, \& Friedman, 1998; 
Lee, Aaker, \& Gardner 2000). Thus, we expect that bonuses and salary increases tied to short-term performance will motivate managers to proactively seek new opportunities to improve performance and to act on them.

H3a: The extent to which annual bonus size depends on short-term performance will be positively related to managers' motivation to act.

H3b: The extent to which salary increases in an organization depend on short-term performance will be positively related to managers' motivation to act.

Frequent evaluations create narrow time frames for managers to prove themselves and can pressure them to act (Andrews \& Smith, 1996). Similarly, short rotation cycles, where managers spend less time managing a brand before moving to another, will incent managers to act quickly to demonstrate their abilities. Therefore,

H4a: The length of period between formal employee evaluations will be negatively related to managers' motivation to act.

H4b: The length of rotation cycles will be negatively related to managers' motivation to act.

Finally, it is important to understand whether cultural characteristics, like strategic orientation and organizational culture, or procedural characteristics, like evaluation and compensation practices, have stronger effects on motivation to act. We do not offer formal predictions, but rather rely on study results to resolve this question.

Several covariates are included in the analysis. Dispositional regulatory focus, which is based on a person's history of achievements, should have an impact on the extent to which managers are willing to be proactive. Second, based on prospect theory (Kahneman \& Tversky, 1979), we argue that managers in competitively successful business units will perceive action as a risky alternative to inaction, thereby becoming less motivated to act compared to managers of less successful business units (e.g., Chattopadhyay, Glick \& Huber, 2001). In this manner, we account for the competitive position of the business unit. Finally, it has been demonstrated that the prolonged stay of managers in the same position makes them more committed to the status quo (Katz, 1982, Smith et al., 1994). Based on this, it is expected that the length of a manager's tenure can negatively influence the motivation to act.

\section{METHOD}

The unit of analysis in our study is the individual manager. A sample of 307 brand managers from US consumer packaged goods companies was invited via e-mail to participate in an online survey. Names and contact information were obtained from the contacts database of a major Midwestern university. Eleven respondents indicated that they were not involved with brand management and 116 completed the survey for a $39.2 \%$ response rate. Because not all respondents were eligible for annual bonuses - one variable of interest - the final sample comprised of 76 respondents. They represented a variety of consumer goods companies. $58.6 \%$ of respondents described their companies as being more profitable than their competition and $55.2 \%$ of the respondents reported a larger market share than their competitors, suggesting a slight skew of the sample toward larger and stronger firms.

Where possible, we used existing measures of constructs, with some measures designed specifically for this study. Motivation to act has been measured using a four-item scale based on the discussion of regulatory focus in Higgins (1997). The theory posits that promotion regulatory focus, associated with high motivation to act, is primed by nurturance needs, strong ideals, and framing of the situation in terms of gains (p. 1283). We used four sevenpoint items to form the scales of motivation to act (the items are reported in Appendix 1). As the items form the concept rather than reflect it (Jarvis, Mackenzie, \& Podsakoff, 2003), scores were summed to obtain the measure of motivation to act.

Strategic orientation was measured using the instrument from Gatignon and Xuereb (1997), with variables constructed as factor scores. Cronbach's alphas were 0.82 for consumer orientation, 0.71 for competitor orientation, and 0.75 for technology orientation. 
We measured organizational culture using Moorman's (1995) 16-item scale. Since items were treated as formative (White, Varadarajan, \& Dacin, 2003), values were computed as the sums of items.

Respondents were asked to provide information on: 1) the extent to which their promotion depended on short-term and long-term performance, 2) the extent to which their annual bonus depended on recent performance, 3) average interval between performance evaluations, and 4) average period between rotations to new assignments. We also asked respondents to indicate the amount of time they spent managing their current brand.

Competitive success was operationalized as the strength of the managed brand relative to its competitors. We adapted a scale from Deshpande, Farley, and Webster's (1993) that assesses a manager's perception of brand size, market share, profitability and growth rate compared to those of the largest competitor. The brand size item was omitted as it was deemed to duplicate the market share item. Items were treated as formative and summed to create a brand strength variable.

Dispositional regulatory focus was measured using four items adopted from the RFQ instrument (e.g., Higgins et al. 2001; Camacho, Higgins, \& Luger, 2003) to reflect promotion and prevention pride of respondents. The former reflects dispositional promotion regulatory focus and the latter, dispositional prevention regulatory focus.

\section{ANALYSIS AND RESULTS}

Table 1 summarizes descriptive statistics and correlations between variables. To test the hypotheses, we used multiple regression where all variables were entered simultaneously. Table 2 shows the regression results. The regression was significant $\left(\mathrm{F}=4.24, \mathrm{p}<0.01, \mathrm{R}^{2}=0.37\right)$ and there was no indication of multicollinearity with the largest value of VIF being 2.06, well below the threshold of 10 suggested by Netter et al. (1996).

Hypotheses H1a, H1c, and H2a were supported - betas are significant and signs are in expected direction. Based on these results, managers tend to be more motivated to act in business units characterized by consumer strategic orientation and adhocracy organizational culture while technology strategic orientation impedes the motivation to act. Interestingly, hypotheses related to the compensation and evaluation procedures were not supported. Bonuses and promotion tied to short-term performance, intervals between evaluations and promotions, and rotation cycle had no impact on the motivation to act.

One covariate was significant; i.e., as expected, managers who demonstrated high promotion pride - an indication of dispositional promotion regulatory focus - tended to be more motivated to act.

\section{DISCUSSION AND LIMITATIONS}

This study adds to the literature on motivational reasons for an active managerial - as opposed to passive position in the workplace. This knowledge allows better understanding of the pace of innovation in some firms and suggests a set of organizational "levers" that top management can use to make their organizations more agile and entrepreneurial. The study contributes to the theory of proactive behavior in the workplace by identifying the situational drivers of managerial willingness to act and comparing the impact of two different groups of drivers cultural and procedural - on this construct. Results extend existing models of managerial decision-making and enrich our understanding of how workplace characteristics and organizational processes influence managers' decisions to engage in proactive - as opposed to passive - behaviors. 


\begin{tabular}{|c|c|c|c|c|c|c|c|c|c|c|c|c|c|c|c|}
\hline & (1) & $(2)$ & (3) & $(4)$ & (5) & (6) & $(7)$ & (8) & (9) & (10) & (11) & (12) & (13) & (14) & (15) \\
\hline Mean & 12.21 & .00 & .00 & .00 & 17.17 & 19.84 & 5.21 & 4.17 & 8.96 & 23.96 & 4.96 & 14.37 & 2.89 & 11.62 & 5.88 \\
\hline Standard deviation & 2.51 & .90 & .84 & .90 & 4.77 & 3.14 & 1.74 & 1.92 & 3.02 & 11.16 & 3.51 & 4.20 & 1.69 & 1.54 & 2.45 \\
\hline (1) Motivation to act & 1 & & & & & & & & & & & & & & \\
\hline (2) Consumer orientation & $.23^{*}$ & 1 & & & & & & & & & & & & & \\
\hline (3) Competitor orientation & .13 & $.28^{* *}$ & 1 & & & & & & & & & & & & \\
\hline (4) Technology orientation & -.12 & $.31^{* *}$ & .20 & 1 & & & & & & & & & & & \\
\hline (5) Adhocracy culture & $.29^{* *}$ & $.37^{* *}$ & $.31^{* *}$ & $.33^{* *}$ & 1 & & & & & & & & & & \\
\hline (6) Market culture & -.15 & .13 & $.34^{* *}$ & $.27^{* *}$ & .15 & 1 & & & & & & & & & \\
\hline (7) Recent performance as a basis of a bonus & .19 & .10 & .03 & .03 & -.07 & -.12 & 1 & & & & & & & & \\
\hline $\begin{array}{l}\text { (8) Extent to which rise depends on short term } \\
\text { performance }\end{array}$ & .20 & .01 & .04 & -.05 & .00 & -.14 & $.40^{* *}$ & 1 & & & & & & & \\
\hline (9) Months b/w formal employee evaluations & -.17 & -.01 & -.13 & -.04 & -.16 & .11 & $.22^{*}$ & .10 & 1 & & & & & & \\
\hline (10) Rotation cycle in months & -.01 & -.15 & -.07 & .05 & -.13 & .09 & $-.23^{*}$ & $-.29^{* *}$ & -.06 & 1 & & & & & \\
\hline (11) Time with brand & .10 & -.06 & -.20 & -.04 & -.11 & -.01 & .13 & .04 & .11 & .08 & 1 & & & & \\
\hline (12) Brand strength as a sum of 3 items & -.07 & .14 & .12 & .15 & .03 & .04 & .13 & -.13 & -.04 & .14 & .06 & 1 & & & \\
\hline $\begin{array}{l}\text { (13) Extent to which rise depends on long-term } \\
\text { performance }\end{array}$ & .11 & .13 & .14 & .19 & .17 & .03 & .17 & $.31^{* *}$ & -.04 & -.11 & .01 & .00 & 1 & & \\
\hline (14) Promotion pride & $.27^{* *}$ & $.26^{*}$ & .20 & .08 & .15 & .17 & -.01 & -.18 & -.01 & -.05 & .02 & -.03 & -.15 & 1 & \\
\hline (15) Prevention pride & $.22^{*}$ & .05 & -.07 & .01 & .17 & .00 & .08 & $-.22^{*}$ & -.11 & .17 & .15 & .07 & $-.30^{* *}$ & .14 & 1 \\
\hline
\end{tabular}


Table 2: Regression Results

\begin{tabular}{|c|c|c|c|}
\hline & Hypotheses & Expected sign & $\begin{array}{l}\text { Regression } \\
\text { coefficient }\end{array}$ \\
\hline \multicolumn{4}{|l|}{ Main effects } \\
\hline Consumer orientation & H1a & + & $0.21 * *$ \\
\hline Competitor orientation & $\mathrm{H} 1 \mathrm{~b}$ & + & 0.11 \\
\hline Technology orientation & $\mathrm{H} 1 \mathrm{c}$ & - & $-0.33 * * *$ \\
\hline Adhocracy culture & $\mathrm{H} 2 \mathrm{a}$ & + & $0.36 * * *$ \\
\hline Market culture & $\mathrm{H} 2 \mathrm{~b}$ & - & $-0.17 *$ \\
\hline Recent performance as a basis of a bonus & $\mathrm{H} 3 \mathrm{a}$ & + & $0.20 *$ \\
\hline $\begin{array}{l}\text { Extent to which rise depends on short term } \\
\text { performance }\end{array}$ & $\mathrm{H} 3 \mathrm{~b}$ & + & 0.14 \\
\hline Months b/w formal emploee evaluations & $\mathrm{H} 4 \mathrm{a}$ & - & -0.15 \\
\hline Rotation cycle in months & $\mathrm{H} 4 \mathrm{~b}$ & - & 0.16 \\
\hline \multicolumn{4}{|l|}{ Covariates } \\
\hline Time with the brand & & & $0.17 *$ \\
\hline Brand strength & & & -0.14 \\
\hline $\begin{array}{l}\text { Extent to which rise depends on long-term } \\
\text { performance }\end{array}$ & & & 0.07 \\
\hline Promotion pride & & & $0.24 * *$ \\
\hline Prevention pride & & & 0.12 \\
\hline $\begin{array}{l}N=76 \\
R^{2}=.37 \\
F=4.24, p<.001\end{array}$ & & & \\
\hline
\end{tabular}

While the effect of cultural factors, like strategic orientation and organizational culture, are, to some extent, intuitive, the lack of support for hypotheses predicting compensation and evaluation procedures effects on managers' motivation to act is of some interest. One possible explanation is that these procedures incent almost force - particular desired behaviors, while the overall active/passive stance of managers may remain unaffected. This result suggests that the proposed construct of managerial motivation to act indeed captures intrinsic motivation of respondents, leaving out the extrinsic factors that may simply push behaviors in desired directions no matter whether an employee is motivated or not. From the standpoint of managerial implications, the fact that cultural factors (organizational culture and strategic orientation) had a stronger effect on managerial motivation to act than procedural factors (compensation and evaluation procedures) suggests the areas that should be prioritized if proactive behaviors are to be encouraged in an organization. Internal motivation goes beyond particular prescribed actions (Bateman \& Crant, 1993) affecting managers' ability to respond to unexpected scenarios and therefore should be more important to cultivate than mere mechanistic responses to instructions and incentives. Based on the results of our study, it seems unlikely that a system of incentives that is not supported by organizational culture will motivate managers to act proactively.

There are several methodological limitations to our study. First, the relatively small sample size lowers the statistical power of the analysis. A larger study may uncover additional relationships overlooked in this one. Second, a new measure of motivation to act was utilized. Even though the new scales demonstrated nomological validity in that the regression was significant and a number of predictions were affirmed, further validation is needed through replication and new studies. Third, data for all variables were obtained from the same source, creating the potential for common method bias. In the context of this study, this problem was difficult to avoid as we wanted to relate an individual's perception of the environment with his or her motivation - all construct internal to each respondent. Attempts to use other sources for such data had a potential to distort the results by not properly reflecting perceptions or motivation.

Finally, further studies need to link motivation to act with managers' actual behavior and identify variables that mediate and moderate this relationship.

\section{ACKNOWLEDGEMENT}

The author would like to express his gratitude to Manfred Maute, Andreas Strebinger, and Pilar Carbonell for their valuable comments and suggestions on this paper." 


\section{AUTHOR INFORMATION}

Dr. Alexander Rusetski received his Ph.D in marketing from Indiana University, USA in 2007. He is currently an Assistant Professor of Marketing at the School of Administrative Studies, York University. Dr. Rusetski's research focuses on marketing strategy and managerial decision-making, and his studies were published in the Journal of International Business Studies and presented on several conferences.

\section{REFERENCES}

1. Andrews, J., \& Smith, D. C. (1996). In Search of the Marketing Imagination: Factors Affecting Creativity of Marketing Programs for Mature Products. Journal of Marketing Research, 33, 174-187.

2. Aspinwall, L. G., \& Taylor, S. E. (1997). A stitch in time: Self-regulation and proactive coping. Psychological Bulletin, 121(3), 417-436.

3. Bateman, T. S., \& Crant, J. M. (1993). The Proactive Component of Organizational Behavior: A Measure and Correlates. Journal of Organizational Behavior, 14, 103-118.

4. Bateman, T. S., \& Crant, M. J. (1999). Proactive behavior: meaning, impact, recommendations. Business Horizons, 42(3), 63-70.

5. Brockner, J., Higgins, E. T., \& Low, M. B. (2004). Regulatory Focus Theory and the Entrepreneurial Process. Journal of Business Venturing, 19, 203-220.

6. Camacho, C. J., Higgins, E. T., \& Luger, L. (2003). Moral Value Transfer From Regulatory Fit: What Feels Right Is Right and What Feels Wrong Is Wrong. Journal of Personality and Social Psychology, 84 (3), 498-510.

7. Chattopadhyay, P., Glick, W. H., \& Huber, G. P. (2001). Organizational Actions in Response to Threats and Opportunities. Academy of Management Journal, 44 (5), 937-955.

8. Crant, J. M. (1995). The proactive personality scale and objective job performance among real estate agents. The Journal of Applied Psychology, 80, 532-537.

9. Crowe, E., \& Higgins, E.T. (1997). Regulatory Focus and Strategic Inclinations: Promotion and Prevention in Decision-Making, Organizational Behavior and Human Decision Processes, 69 (2), 117 132.

10. De Jong, A., \& de Ruyter, K. (2004). Adaptive versus Proactive Behavior in Service Recovery: The Role of Self Managing Teams. Decision Sciences, 35 (3), 457-491.

11. Deshpande, R., Farley, J. U., \& Webster, F. E. (1993). Corporate Culture, Customer Orientation, and Innovativeness in Japanese Firms: A Quadrad Analysis. Journal of Marketing, 57 (January), 23-37.

12. _ \& Webster, Jr., F. E. (1989). Organizational Culture and Marketing: Defining the Research Agenda. Journal of Marketing, 53 (January), 3-15

13. Gatignon, H. \& Xuereb, J.-M. (1997). Strategic Orientation of the Firm and New Product Performance. Journal of Marketing Research, 34 (February), 77-90.

14. Higgins, E. T. (1997). Beyond Pleasure and Pain. American Psychologist, 52 (December), 1280-1300.

15. $\quad$ Friedman, R. S., Harlow, R. E., Idson, L. C., Ayduk, O. N., \& Tailor, A. (2001). Achievemnet Orienttaions from Subjective Histories of Success: Promotion Pride versus Prevention Pride. European Journal of Social Psychology, 31, 3-23.

16. _ Shah, J., \& Friedman, R. (1997). Emotional responses to goal attainment: Strength of regulatory focus as moderator. Journal of Personality and Social Psychology, 72(3), 515-525.

17. Jarvis, C. B., Mackenzie, S. B., \& Podsakoff, P. M. (2003). A Critical Review of Construct Indicators and Measurement Model Misspecification in Marketing and Consumer Research. Journal of Consumer Research, 30 (September), 199-218.

18. Jensen, M. C., \& Meckling, W. H. (1976). Theory of the Firm: Managerial Behavior, Agency Costs and Ownership Structure. Journal of Financial Economics, 3, 305-360.

19. Kahneman, D., \& Tversky, A. (1979). Prospect Theory: An Analysis of Decision Under Risk. Economentrica, 47 (2), 263-291.

20. Katz, R. (1982). The Effect of Group Longevity on Project Communication and Performance. Administrative Science Quarterly, 27, 81-104.

21. Kim, T., Hon, A. H. Y., \& Crant, J. M. (2009). Proactive Personality, Employee Creativity, and Newcomer Outcomes: A Longitudinal Study. Journal of Business and Psychology, 24, 93-103.

22. Kirkman, B.L., \& Rosen, B. (1999). Beyond Self-Management: Antecedents and Consequences of Team Empowerment. Academy of Management Journal, 41 (1), 58-74. 
23. Lee, A. Y., Aaker, J. L., \& Gardner, W. L. (2000). The Pleasures and Pains of Distinct Self-Construals: The Role of Interdependence in Regulatory Focus. Journal of Personality and Social Psychology, 78 (6), 1122-1134.

24. Martynov, A. (2009). Agents or Stewards? Linking Managerial Behavior and Moral Development. Journal of Business Ethics, 90, 239-249.

25. Moorman, C. (1995). Organizational Market Information Processing: Cultural Antecedents and New Product Outcomes. Journal of Marketing Research, 32 (August), 318-335.

26. Narver, J. C., \& Slater, S. F. (1990). The effect of a market orientation on business profitability. Journal of Marketing, 54(4), 20-35

27. Neter, J., Kutner, M. H., Nachtsheim, C. J., \& Wasserman, W. (1996). Applied Linear Statistical Models. New York: WCB/McGraw-Hill

28. Noble, C. H., Sinha, R. K., \& Kumar, A. (2002). Market orientation and alternative strategic orientations: A longitudinal assessment of performance implications. Journal of Marketing, 66(4), 2539.

29. Shah, J., Higgins, E. T., \& Friedman, R. (1997). Performance Incentives and Means: How Regulatory Focus Influences Goal Attainment. Journal of Personality and Social Psychology, 74 (2), 285-293.

30. Smith, K. G., Smith, K. A., Olian, J. D., \& Sims, H. P. (1994). Top management team demography and process: The role of social integration and communication. Administrative Science Quarterly, 39(3), 412-438.

31. White, J. C., Varadarajan, P. R., \& Dacin, P. A. (2003). Market Situation Interpretation and Response: The Role of Cognitive Style, Organizational Culture, and Information Use. Journal of Marketing, 67 (3), 63-79. 


\section{APPENDIX 1: MOTIVATION TO ACT SCALES}

For each pair of statements please indicate which better describes your feelings about your job: (Fivepoint items anchored at)

1. In my job, it is imperative to make sure that nothing bad happens as a result of my decisions $\leftarrow \rightarrow$ In my job, it is imperative that my decisions lead to immediate and tangible positive outcomes.

2. Mistakes and errors are a natural part of my job and can be tolerated $\leftarrow \rightarrow$ The price of an error is too high in my work, so mistakes should be avoided at all costs.

3. I would rather grab the opportunity when it presents itself than waste time contemplating the possibility of failure $\leftarrow \rightarrow$ I would rather wait than rush into action that carries some risk of negative outcomes.

4. My choices are motivated primarily by my desire to demonstrate my ability as a manager $\leftarrow \rightarrow$ The possibility of failing in my job is my primary motivation. 